\title{
SISTEM INFORMASI BERBASIS WEB PADA TEMPAT ZIARAH GOA MARIA LOURDES SENDANGSONO KULONPROGO
}

\author{
Yohana Desy Chrissetiyantari, Elly Muningsih \\ Universitas Bina Sarana Informatika \\ Email : ydesychrist@gmail.com, elly.emh@bsi.ac.id
}

\begin{abstract}
In Goa Maria Catholicism the center for pilgrimage and devotion to Mary, its existence has a long history. Goa Maria Lourdes Sendangsono is one of the pilgrimage places visited by many Catholics, because of the availability of prayer facilities that support comfort on pilgrimage. Another interesting thing is the prayer service box that is provided for pilgrims who want to submit prayer requests, which later will be prayed for during the Eucharistic service. But the prayer service box is considered to be less effective and efficient than that as well as a lack of information for pilgrims about Goa Maria Lourdes Sendangsono. This website is expected to make it easier for pilgrims to get information about Goa Maria Lourdes Sendangsono and facilitate the delivery of prayer requests online. Data collection methods used in research include observation, interviews, literature studies and documentation. While the software development method uses the waterfall method. In the end, the information system of the web-based Pilgrimage Site of Goa Maria Lourdes Sendangsono is an effective and efficient means of information because it covers a wider area.
\end{abstract}

\section{Keywords : prayer requests, website, waterfall method, means of information}

\begin{abstract}
Abstrak - Di dalam Agama Katolik Goa Maria menjadi pusat untuk berziarah dan devosi kepada Maria, keberadaannya mempunyai sejarah panjang. Seperti Goa Maria Lourdes Sendangsono yang menjadi salah satu tempat ziarah yang banyak dikunjungi oleh orang Katolik, karena tersedianya fasilitas-fasilitas doa yang mendukung kenyamanan dalam berziarah. Hal menarik lainnya yaitu kotak layanan doa yang disediakan bagi peziarah yang ingin menyampaikan permohonan doa, yang nantinya doa akan diujubkan pada saat ibadah Ekaristi. Namun kotak layanan doa dirasa kurang efektif dan efisien selain itu juga kurangnya informasi bagi peziarah tentang Goa Maria Lourdes Sendangsono. Perancangan website ini diharapkan dapat memudahkan peziarah mendapatkan informasi seputar Goa Maria Lourdes Sendangsono serta memudahkan penyampaian permohonan doa secara online. Metode pengumpulan data yang digunakan dalam penelitian antara lain dengan observasi, wawancara, studi pustaka dan dokumentasi. Sedangkan metode pengembangan perangkat lunak menggunakan metode waterfall. Pada akhirnya sistem informasi Tempat Ziarah Goa Maria Lourdes Sendangsono berbasis web sebagai sarana informasi yang efektif dan efisien karena mencakup wilayah yang lebih luas.
\end{abstract}

Kata Kunci : permohonan doa, website, metode waterfall, sarana informasi

\section{A. PENDAHULUAN}

Ziarah merupakan salah satu praktik dari sebagian umat beragama yang memiliki makna moral yang penting. Dalam tradisi Agama Katolik, Goa Maria sebagai pusat untuk melakukan ziarah dan devosi kepada Maria. Seperti Goa Maria Lourdes Sendangsono yang menjadi tempat pembaptisan pertama bagi orang Jawa. Umat Katolik setempat percaya bahwa berdoa di Goa Maria Lourdes Sendangsono dapat memberikan dampak positif akan iman dan keyakinan. Yang menarik dari tempat ziarah Goa Maria Lourdes Sendangsono untuk dikunjungi para peziarah adalah fasilitas-fasilitas doa yang menjadi sarana pendukung kenyaman dalam berziarah dan berdevosi seperti Gereja St. Maria Lourdes Promasan, Padusan, Kapel Maria, Jalan Salib Panjang, Jalan Salib Pendek dan lain-lain yang ada di Tempat Ziarah Goa Maria Lourdes
Sendangsono. Hal menarik lainnya adalah Goa Maria Lourdes Sendangsono menyediakan kotak layanan doa sehingga para peziarah dapat menyampaikan permohonan doa dengan menuliskannya di dalam kotak layanan doa tersebut, yang nantinya akan diujubkan pada saat ibadah Ekaristi. Namun kotak layanan doa tersebut kurang efektif dan efisien karena hanya dibuka sebulan sekali. Selain itu, kotak layanan doa hanya dapat dimanfaatkan oleh umat Katolik setempat dan peziarah untuk menyampaikan doa-doa. Karena kurangnya informasi mengenai tempat ziarah Goa Maria Lourdes Sendangsono menjadikan umat Katolik tidak mendapatkan informasi secara jelas sehingga perlu dibuat media alternatif untuk menginformasikan tempat ziarah Goa Maria Lourdes Sendangsono yang berada di Kulon Progo. Penelitian ini bertujuan untuk merancang dan membangun sebuah sistem informasi berbasi web untuk Goa Maria 
Lourdes Sendangsono agar memudahkan umat Katolik mengakses informasi dan mengirimkan doa secara online.

\section{B. TINJAUAN PUSTAKA}

1. Internet dan Web

Menurut Kadir (2014), Internet adalah jaringan terbesar yang menghubungkan jutaan komputer yang saling berhubungan di seluruh penjuru dunia dan tidak terikat pada satu organisasi pun. Sedangkan web adalah salah sauatu aplikasi yang berisikan dokumendokumen multimedia seperti teks, gambar, suara, animasi, video yang didalamnya menggunakan protokol HTTP (hypertext transfer protocol), sedangkan untuk mengaksesnya menggunakan perangkat lunak yang disebut browser (Arief, 2011). Web diartikan juga sebagai bagian visual dari Internet seperti televisi, radio CB (citizen band), kantor pos, majalah, buletin yang tercakup di dalamnya untuk memudahkan akses ke database dan arsip yang dapat menampilkan informasi, file suara digital, karya seni dan bahkan klip film (Purnama, 2016).

\section{Sistem Informasi}

Menurut Sutabri (2012) menyatakan bahwa sistem Informasi didefinisikan sebagai suatu sistem di dalam suatu organisasi yang mempertemukan kebutuhan pengolahan transaksi harian guna mendukung fungsi operasi yang bersifat manajerial dengan kegiatan strategi dari suatu organisasi untuk dapat menyediakan laporan-laporan yang diperlukan oleh pihak luar tertentu". Sistem informasi mencakup komponenkomponen seperti manusia, komputer, teknologi informasi, dan prosedur kerja yang diproses dari suatu data menjadi suatu informasi untuk mencapai suatu sasaran atau tujuan (Kadir, 2014).

\section{Pengujian}

Pengujian sistem didefinisikan sebagai proses mengeksekusi sistem perangkat lunak untuk menentukan apakah sistem perangkat lunak tersebut cocok dengan spesifikasi sistem dan berjalan sesuai dengan lingkungan yang diinginkan atau tidak (Fatta, 2007). Pengujian sistem sering diasosisikan dengan bug, ketidaksempurnaan program, kesalahan pada baris program yang menyebabkan kegagalan pada eksekusi sistem perangkat lunak.

\section{METODE PENELITIAN}

Metode Penelitian yang digunakan dalam penelitian ini ada dua yaitu metode pengumpulan data dan metode pengembangan perangkat lunak. Adapun metode yang dimaksud adalah : a. Metode yang digunakan dalam pengumpulan data dan informasi adalah:

1. Pengamatan (Observasi)

Dalam metode ini penulis melakukan pengamatan dan penelitian dengan cara berkunjung langsung ke lokasi tempat ziarah Goa Maria Lourdes Sendangsono sehingga memperoleh informasi yang jelas dan lengkap mengenai jadwal ekaristi, pengurus dan layanan doa yang ada di tempat ziarah Goa Maria Lourdes Sendangsono.

2. Wawancara (Interview)

Wawancara merupakan salah satu metode pengumpulan data dengan melakukan tanya jawab secara langsung kepada narasumber yang bersangkutan. Adapun narasumber yang diikutsertakan diantaranya Ibu Maria Kristanti selaku sekretaris pengurus peziarahan Goa Maria Lourdes Sendangsono.

3. Studi Pustaka (Literature)

Metode ini digunakan penulis agar mendapatkan sumber referensi yang baik berupa buku-buku dengan cara membaca dan mempelajari buku-buku yang berkaitan dengan permasalahan informasi yang diangkat penulis.

4. Dokumentasi (Documentation)

Penulis menggunakan metode ini untuk memperjelas informasi dengan cara mengambil gambar atau foto terkait sejarah, fasilitas doa dan lingkungan sekitar tempat ziarah.

b. Metode pengembangan perangkat lunak ini menggunakan model waterfall yang terbagi menjadi lima tahapan (Sukamto dan Shalahuddin, 2013), yaitu:

1. Analisa kebutuhan perangkat lunak Pada tahap ini dilakukan pengumpulan data mengenai spesifikasi perangkat lunak seperti apa yang dibutuhkan oleh user.

2. Desain

Pada tahap ini dilakukan perancangan berupa perancangan database, perancangan tampilan antar muka serta perancangan sistem berjalan.

\section{a. Perancangan Database}

Terdapat 3 rancangan basis data pada pembuatan website Tempat Ziarah Goa Maria Lourdes Sendangsono diantaranya adalah Entity Relationship Diagram (ERD), Logical Record Structure (LRS) dan Spesifikasi File. Dibawah ini ditampilkan gambar rancangan ERD dan LRS : 


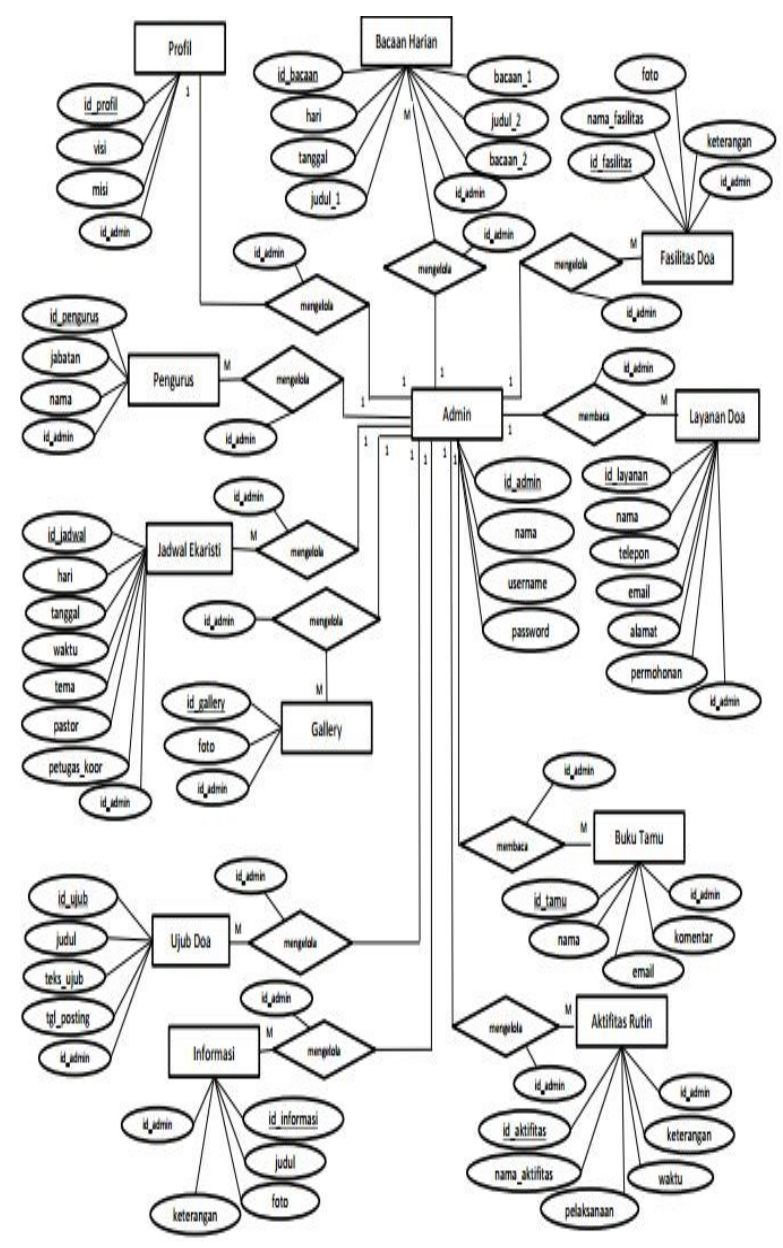

Gambar III. 1. Entity Relationship Diagram (ERD)

\section{a. Logical Record Structure (LRS)}

b. Perancangan Tampilan

Rancangan antarmuka merupakan gambar yang dapat memberikan kemudahan bagi penulis dalam perancangan website. Rancangan

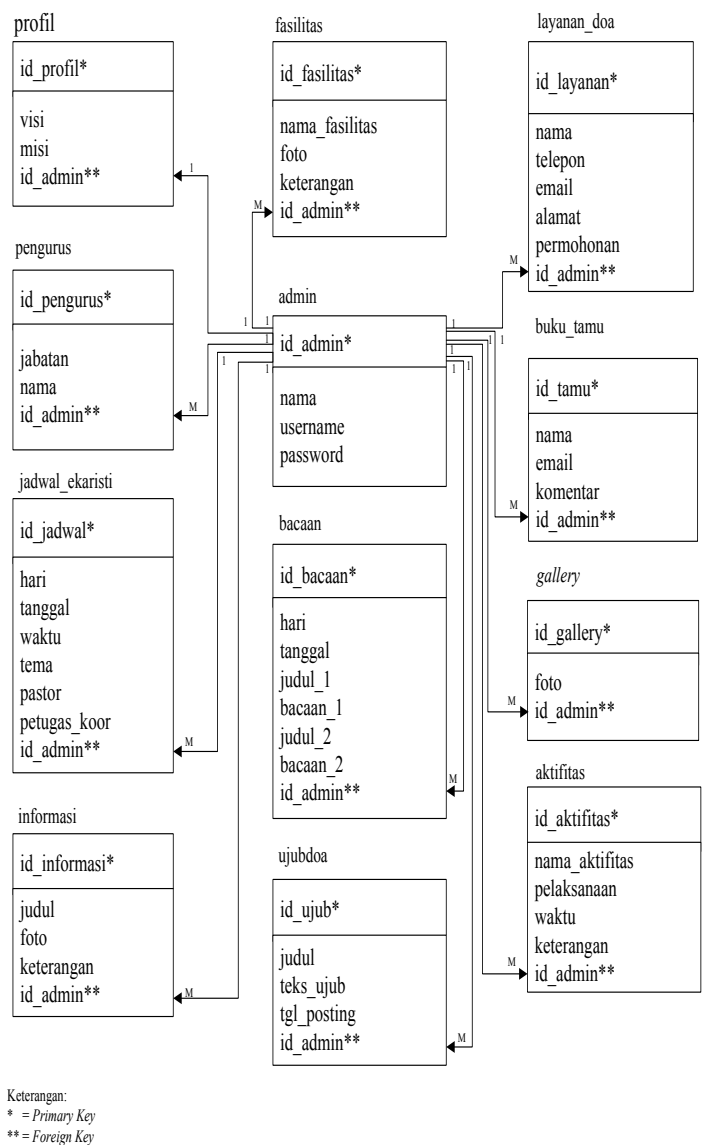

Gambar III.2. Logical Record Structure (LRS) antarmuka dalam website yang penulis buat terbagi menjadi 2 (dua), yaitu rancangan antarmuka pengguna (user) dan rancangan antarmuka admin.

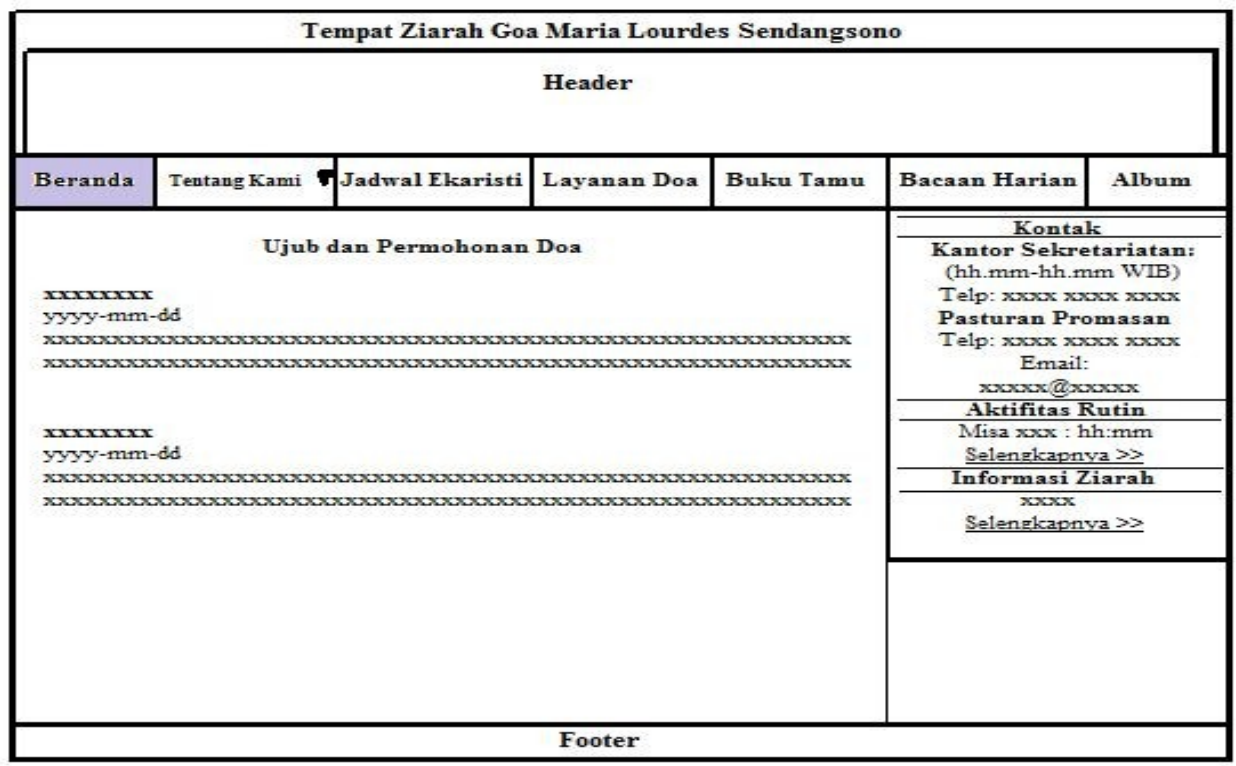

Gambar III.3. Rancangan Antarmuka Pengguna User 


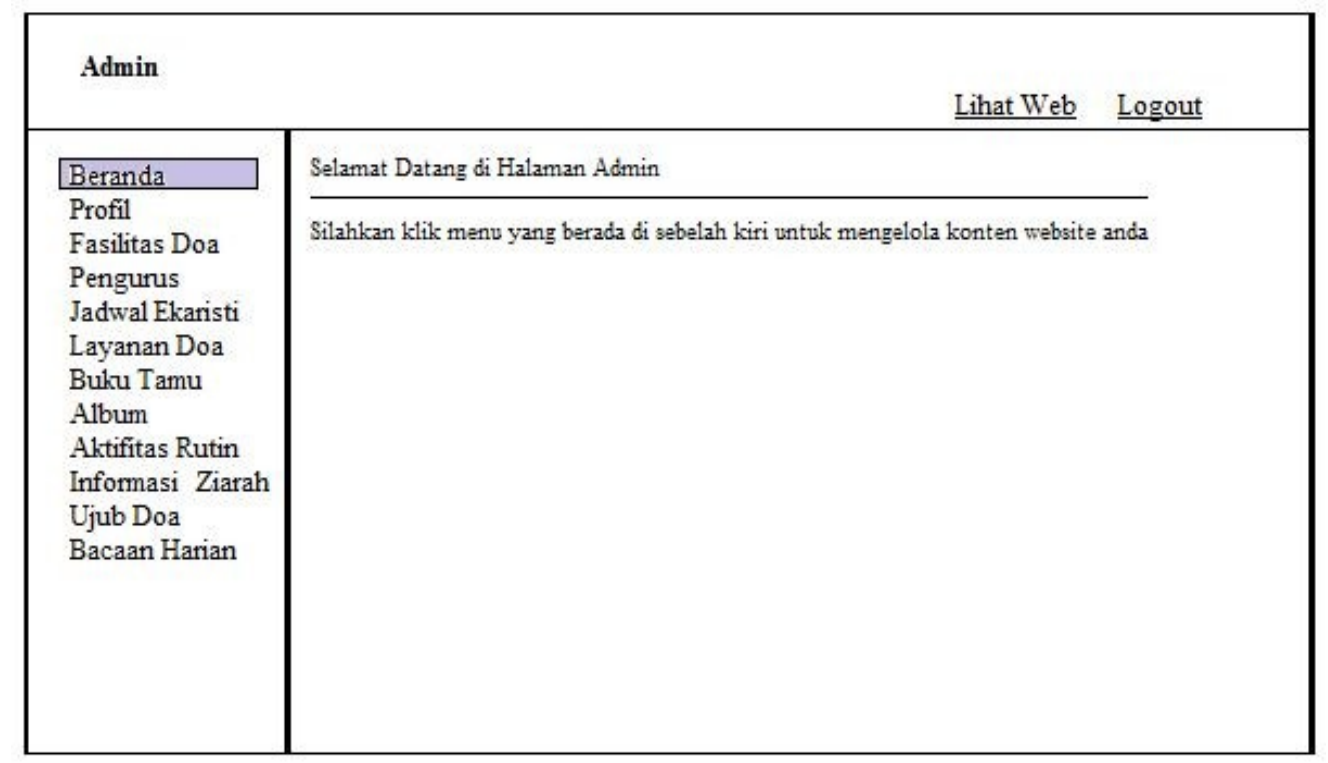

Gambar III.4. Rancangan Antarmuka Admin

3. Pembuatan kode program

Pada tahap ini desain ditranslansikan ke dalam perangkat lunak yang menghasilkan program komputer yang sesuai dengan desain yang telah dibuat.

4. Pengujian

Pada tahap ini, program akan diuji coba untuk memastikan tidak ada kesalahan serta sesuai dengan yang diinginkan.

\section{PEMBAHASAN}

\section{Analisa Kebutuhan}

Tujuan dari analisis yaitu memahami dengan sebenar-benarnya kebutuhan dari sistem serta mengembangkan sebuah sistem yang mewadahi kebutuhan tersebut, atau memutuskan bahwa sebenarnya pengembangan sistem baru tidak dibutuhkan (Fatta, 2007). Menurut Fatta (2007) kebutuhan sistem dibagi menjadi dua jenis, yaitu kebutuhan fungsional dan kebutuhan nonfungsional. Dalam analisa kebutuhan fungsional pengguna website diperlukan analisa kebutuhan pengguna (user) yaitu :

Admin dapat login username dan password untuk mengelola profil, fasilitas, pengurus, jadwal ekaristi, album, aktifitas rutin, informasi, ujub doa dan bacaan harian yang ada di dalam halaman administrator.

User dapat melihat profil, fasilitas, pengurus, jadwal ekaristi, album, aktifitas rutin, informasi, ujub doa dan bacaan harian serta melakukan permohonan doa di dalam layanan doa dan mengisi buku tamu.

Dalam kebutuhan non-fungsional menjelaskan tentang kebutuhan yang berisi properti perilaku yang dimiliki oleh sistem, diantaranya:

1. Operasional

a. Digunakan pada sistem operasi Microsoft Windows 7.

b. Spesifikasi komputer Intel Pentium.

c. RAM 256-512.

d. Website dapat diakses melalui web browser seperti Mozila Firefox, Google Chrome, dan sebagainya.

\section{Keamanan}

Terdapat username dan password untuk login admin.

3. Informasi

Digunakan untuk menginformasikan apabila user yakin akan mengirim layanan doa.

\section{Rancangan Struktur Navigasi}

Dalam perancangan website Tempat Ziarah Goa Maria Lourdes Sendangsono diperlukan dua rancangan struktur navigasi user dan struktur navigasi admin. Struktur navigasi user berguna untuk mengetahui apa saja informasi yang dapat diakses oleh user sedangkan struktur navigasi admin berguna untuk mengetahui langkah apa yang dapat dikerjakan oleh admin. Berikut gambar rincian dari kedua struktur tersebut: 


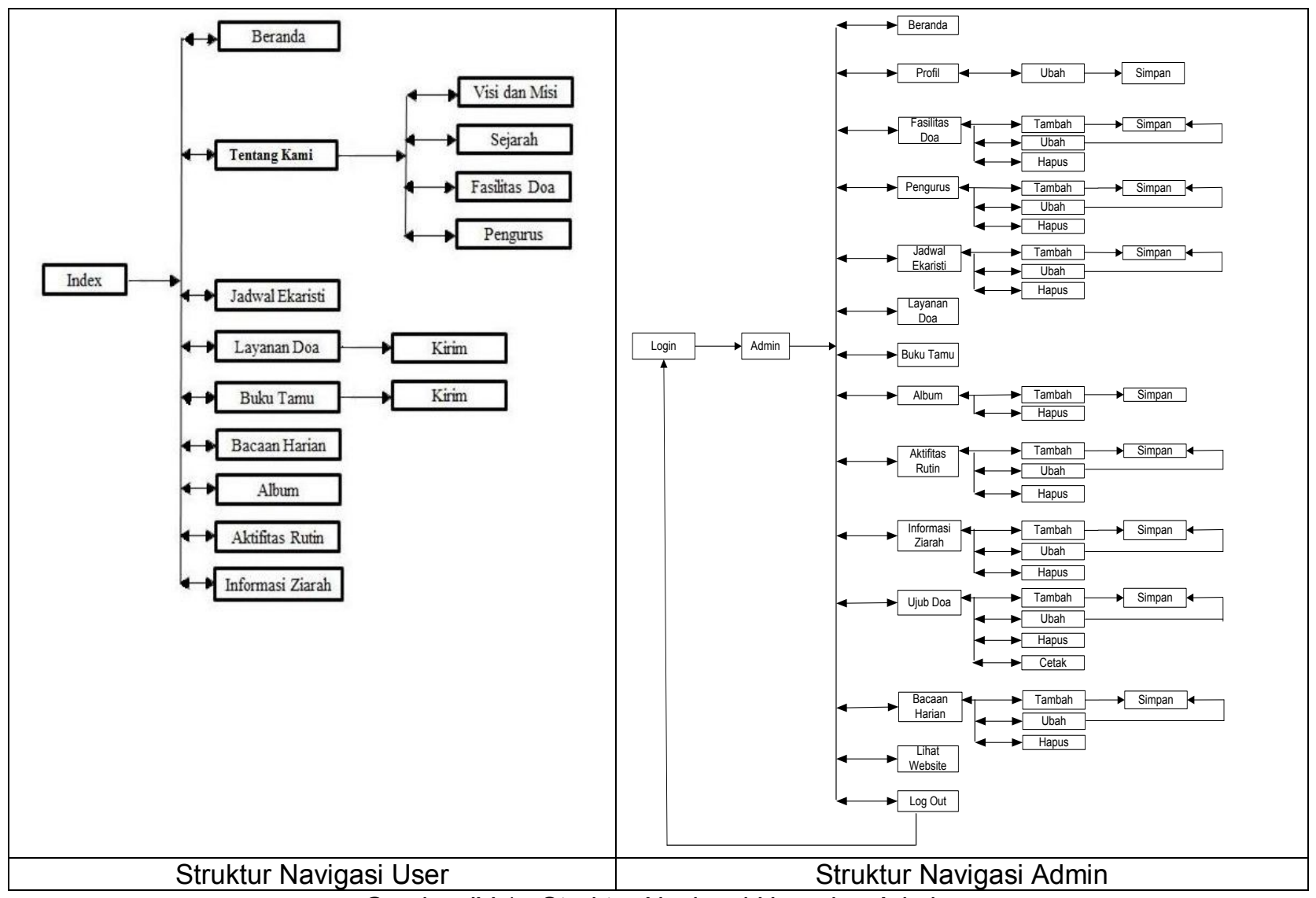

Gambar IV.1. Struktur Navigasi User dan Admin

\section{Pengujian Unit}

Pengujian terhadap program yang dibuat menggunakan blackbox testing yang fokus terhadap proses masukan dan keluaran program.
Beberapa pengujian unit yang dilakukan, antara lain :

a. Pengujian Unit Form Login Admin

Tabel IV.1. Tabel Hasil Pengujian Black Box Testing Halaman Login Admin

\begin{tabular}{|c|c|c|c|c|c|}
\hline No & Skenario Pengujian & Test case & Hasil yang diharapkan & $\begin{array}{c}\text { Hasil } \\
\text { Pengujian }\end{array}$ & Kesimpulan \\
\hline 1 & $\begin{array}{l}\text { Username dan } \\
\text { password dikosongkan } \\
\text { kemudian pilih tombol } \\
\text { login }\end{array}$ & $\begin{array}{l}\text { Username: (kosong) } \\
\text { Password: (kosong) }\end{array}$ & $\begin{array}{l}\text { Sistem akan menolak } \\
\text { admin dan menampilkan } \\
\text { "Please fill out this field" } \\
\text { pada kolom yang masih } \\
\text { kosong }\end{array}$ & $\begin{array}{l}\text { Sesuai } \\
\text { Harapan }\end{array}$ & Valid \\
\hline 2 & $\begin{array}{l}\text { Username dikosongkan } \\
\text { dan password diisi } \\
\text { kemudian di pilih } \\
\text { tombol login }\end{array}$ & $\begin{array}{l}\text { Username: } \\
\text { admin (kosong) } \\
\text { Password: } \\
* * * * * \text { (benar) }\end{array}$ & $\begin{array}{l}\text { Sistem akan menolak } \\
\text { admin dan menampilkan } \\
\text { "Please fill out this field" } \\
\text { pada kolom yang masih } \\
\text { kosong }\end{array}$ & $\begin{array}{l}\text { Sesuai } \\
\text { Harapan }\end{array}$ & Valid \\
\hline 3 & $\begin{array}{l}\text { Username diisi dan } \\
\text { password diisi (salah) } \\
\text { kemudian di pilih } \\
\text { tombol login }\end{array}$ & $\begin{array}{l}\text { Username: } \\
\text { admin (benar) } \\
\text { Password: } \\
* \star * \star \star \text { (salah) }\end{array}$ & $\begin{array}{l}\text { Sistem akan menolak } \\
\text { admin dan menampilkan } \\
\text { "Gagal login" }\end{array}$ & $\begin{array}{l}\text { Sesuai } \\
\text { Harapan }\end{array}$ & Valid \\
\hline 4 & $\begin{array}{l}\text { Username dan } \\
\text { password diisi } \\
\text { kemudian dipilih tombol } \\
\text { login }\end{array}$ & $\begin{array}{l}\text { Username: (salah) } \\
\text { Password: }{ }^{* * * *} \text { (salah) }\end{array}$ & $\begin{array}{l}\text { Sistem akan menolak } \\
\text { admin dan menampilkan } \\
\text { "Gagal login" }\end{array}$ & $\begin{array}{l}\text { Sesuai } \\
\text { Harapan }\end{array}$ & Valid \\
\hline 5 & $\begin{array}{l}\text { Username dan } \\
\text { password diisi dengan } \\
\text { benar kemudian dipilih } \\
\text { tombol login }\end{array}$ & $\begin{array}{l}\text { Username: admin } \\
\text { (benar) } \\
\text { Password: }{ }^{* * * * *} \text { (benar) }\end{array}$ & $\begin{array}{l}\text { Sistem menerima dan } \\
\text { masuk ke halaman } \\
\text { beranda admin }\end{array}$ & $\begin{array}{l}\text { Sesuai } \\
\text { Harapan }\end{array}$ & Valid \\
\hline
\end{tabular}


b. Pengujian Unit Tambah Fasilitas

Tabel IV.2. Tabel Hasil Pengujian Black Box Testing Halaman Tambah Fasilitas

\begin{tabular}{|c|c|c|c|c|c|}
\hline No & $\begin{array}{l}\text { Skenario } \\
\text { Pengujian }\end{array}$ & Test case & $\begin{array}{l}\text { Hasil yang } \\
\text { diharapkan }\end{array}$ & $\begin{array}{c}\text { Hasil } \\
\text { Pengujian }\end{array}$ & Kesimpulan \\
\hline 1 & $\begin{array}{l}\text { Semua kolom } \\
\text { dikosongkan } \\
\text { kemudian pilih } \\
\text { tombol simpan }\end{array}$ & $\begin{array}{l}\text { Nama Fasilitas: } \\
\text { (kosong) } \\
\text { File Foto: (kosong) } \\
\text { Keterangan: } \\
\text { (kosong) }\end{array}$ & $\begin{array}{l}\text { Sistem akan } \\
\text { memberi peringatan } \\
\text { "Please fill out this } \\
\text { field" pada kolom } \\
\text { nama fasilitas dan } \\
\text { keterangan serta } \\
\text { peringatan "Please } \\
\text { select a file" pada } \\
\text { kolom file foto }\end{array}$ & $\begin{array}{l}\text { Sesuai } \\
\text { Harapan }\end{array}$ & Valid \\
\hline 2. & $\begin{array}{l}\text { Salah satu } \\
\text { kolom } \\
\text { dikosongkan } \\
\text { kemudian pilih } \\
\text { tombol simpan }\end{array}$ & $\begin{array}{l}\text { Nama Fasilitas: } \\
\text { (kosong) } \\
\text { File Foto: (diisi) } \\
\text { Keterangan: (diisi) }\end{array}$ & $\begin{array}{l}\text { Sistem akan } \\
\text { memberi peringatan } \\
\text { "Please fill out this } \\
\text { field" pada kolom } \\
\text { yang masih kosong }\end{array}$ & $\begin{array}{l}\text { Sesuai } \\
\text { Harapan }\end{array}$ & Valid \\
\hline 3. & $\begin{array}{l}\text { Semua kolom } \\
\text { diisi kemudian } \\
\text { dipilih tombol } \\
\text { simpan }\end{array}$ & $\begin{array}{l}\text { Nama Fasilitas: } \\
\text { (diisi) } \\
\text { File Foto: (diisi) } \\
\text { Keterangan : (diisi) }\end{array}$ & $\begin{array}{l}\text { Sistem menerima } \\
\text { dan menampilkan } \\
\text { "Fasilitas doa } \\
\text { berhasil disimpan" } \\
\text { dan tersimpan ke } \\
\text { dalam database }\end{array}$ & $\begin{array}{l}\text { Sesuai } \\
\text { Harapan }\end{array}$ & Valid \\
\hline
\end{tabular}

\section{E. KESIMPULAN}

Dengan terciptanya website Tempat Ziarah Goa Maria Lourdes Sendangsono, user dapat dengan mudah mengakses informasi seputar Tempat Ziarah Goa Maria Lourdes Sendangsono dan dimudahkan juga dengan adanya permohonan doa secara online. Walaupun hasil yang diharapkan sudah terpenuhi, namun untuk penelitian lebih lanjut bisa dikembangkan dengan sistem informasi berbasis Android.

\section{DAFTAR PUSTAKA}

[1] Arief, M. Rudyanto. 2011. Pemrograman Web Dinamis Menggunakan PHP dan MySQL. Yogyakarta: Penerbit Andi.

[2] Fatta, Hanif Al. 2007. Analisis dan Perancangan Sistem Informasi. Yogyakarta: Penerbit Andi

[3] Kadir, Abdul. 2014. Pengenalan Sistem Informasi. Yogyakarta: Penerbit Andi.

[4] Purnama, Bambang Eka. 2010.Konsep Dasar Internet. Yogyakarta: Teknosain.

[5] Sukamta, Rosa A. dan M. Shalahuddin. 2013. Rekayasa Perangkat Lunak Terstruktur \& Beorientasi Objek. Bandung: Informatika Bandung.

[6] Sutabri, Tata. 2012. Analisis Sistem Informasi. Yogyakarta: Penerbit Andi. 